\title{
UM ESTUDO SOBRE OS DECRETOS LEGISLATIVOS: PROCEDIMENTO, TRATADOS INTERNACIONAIS COMUNS E CONTROLE DE CONSTITUCIONALIDADE
}

\author{
Jamile Gonçalves Calissi
}

jamilecalissi@yahoo.com.br

\begin{abstract}
RESUMO
O presente artigo propõe uma análise completa, analítica e apurada sobre a espécie legislativa apontada no artigo 59 da Constituição Federal denominada decreto legislativo, apresentando todo o seu procedimento geral, instruído pelo Regimento Interno Comum do Congresso Nacional, bem como aquele empreendido na aprovação de tratados internacionais comuns, em contrapartida aos tratados internacionais sobre direitos humanos, aprovados por votação diferenciada equiparada a uma emenda constitucional. Ao final, aborda a questão do controle de constitucionalidade afeita ao assunto, explicando a possibilidade de fiscalização abstrata de constitucionalidade sobre os decretos legislativos e concluindo pela impossibilidade de tal fiscalização diretamente sobre os tratados internacionais.
\end{abstract}

Palavras-chave: direito - direito constitucional - espécie legislativa

\begin{abstract}
This article proposes a complete, analytical and accurate analysis of the legislative species pointed out in article 59 of the Federal Constitution called legislative decree, presenting its whole general procedure, instructed by the Common Bylaws of the National Congress, as well as that one undertaken in the adoption of common international treaties, in contrast to the international human rights treaties, approved by separate vote treated as a constitutional amendment. In the end, it deals with the issue of constitutionality control accustomed to the subject, explaining the possibility of abstract oversight on the constitutionality of the legislative decrees and concluding for the impossibility of such an oversight directly on international treaties.
\end{abstract}

Keywords: law - constitutional Law - legislative species

\section{DECRETO LEGISLATIVO}

O decreto legislativo, espécie normativa prevista no artigo 59, VI, é o instrumento que viabiliza a atuação do Congresso Nacional ${ }^{1}$.

\footnotetext{
${ }^{1}$ Art. 59. O processo legislativo compreende a elaboração de:

I - emendas à Constituição;

II - leis complementares;

III - leis ordinárias;

IV - leis delegadas;

$\mathrm{V}$ - medidas provisórias;
} 
Assim pode ser compreendido sob dois aspectos.

Primeiramente, tendo em vista uma concepção mais abrangente e, ainda sob os resquícios da Constituição de 1967 e posterior emenda constitucional $n^{\circ} 1$ de 1969, a referida espécie normativa, dita lato senso, é todo ato do Congresso Nacional para a elaboração legislativa demarcado pela não exigibilidade da sanção (promulgação ou veto) presidencial. Nos dizeres de Pontes de Miranda, "decretos legislativos são as leis a que a Constituição não exige a remessa ao Presidente da República para a sanção (promulgação ou veto)”"2.

Já sob a égide da Constituição contemporânea, por meio de uma interpretação dos artigos $48^{3}$ (que dispõe expressamente sobre a necessidade de sanção do Presidente da República) e 49 (que não prevê a sanção), pode-se também entender o decreto legislativo como sendo todo o procedimento no Congresso, para a elaboração legislativa, que prescinda da sanção do chefe do Executivo.

Entretanto, somente essa visão aberta não basta para explicitar adequadamente tal espécie normativa.

\footnotetext{
VI - decretos legislativos;

VII - resoluções.

Parágrafo único. Lei complementar disporá sobre a elaboração, redação, alteração e consolidação das leis.

${ }^{2}$ MIRANDA, Pontes de. Comentários à Constituição de 1967. Tomo III, São Paulo: Revista dos Tribunais, 1973 , p. 142.

${ }^{3}$ Art. 48. Cabe ao Congresso Nacional, com a sanção do Presidente da República, não exigida esta para o especificado nos arts. 49, 51 e 52, dispor sobre todas as matérias de competência da União, especialmente sobre: I - sistema tributário, arrecadação e distribuição de rendas;

II - plano plurianual, diretrizes orçamentárias, orçamento anual, operações de crédito, dívida pública e emissões de curso forçado;

III - fixação e modificação do efetivo das Forças Armadas;

IV - planos e programas nacionais, regionais e setoriais de desenvolvimento;

V - limites do território nacional, espaço aéreo e marítimo e bens do domínio da União;

VI - incorporação, subdivisão ou desmembramento de áreas de Territórios ou Estados, ouvidas as respectivas Assembléias Legislativas;

VII - transferência temporária da sede do Governo Federal;

VIII - concessão de anistia;

IX - organização administrativa, judiciária, do Ministério Público e da Defensoria Pública da União e dos Territórios e organização judiciária, do Ministério Público e da Defensoria Pública do Distrito Federal;

$\mathrm{X}$ - criação, transformação e extinção de cargos, empregos e funções públicas, observado o que estabelece o art. $84, \mathrm{VI}, b$;

XI - criação e extinção de Ministérios e órgãos da administração pública;

XII - telecomunicações e radiodifusão;

XIII - matéria financeira, cambial e monetária, instituições financeiras e suas operações;

XIV - moeda, seus limites de emissão, e montante da dívida mobiliária federal.

XV - fixação do subsídio dos Ministros do Supremo Tribunal Federal, observado o que dispõem os arts. 39 , $\S 4^{\circ}$; 150 , II; 153 , III; e $153, \S 2^{\circ}$, I.
} 
Tem-se, assim, que decreto legislativo é o instrumento pelo qual o Congresso Nacional veicula as matérias que são de sua competência exclusiva. Essas matérias vêm dispostas no artigo 49 da Constituição Federal ${ }^{4}$.

Além do mais, os decretos legislativos também foram previstos como instrumentos de regulamentação das relações jurídicas decorrentes do período de eficácia das medidas provisórias, antes de sua conversão em lei. É o que dispunha o antigo parágrafo único do artigo 62 da Constituição Federal, com entendimento estipulado pela Resolução no 1/89 do Congresso Nacional. Com a emenda constitucional $n^{\circ} 32$ e conseqüente adição de doze novos parágrafos ao referido artigo, em substituição a um único parágrafo anteriormente existente, a competência do Congresso Nacional para regulamentar tais relações decorrentes de medida provisória por meio de decreto legislativo se manteve, entretanto, agora de maneira expressa no texto constitucional (artigo 62, $\S 3^{\circ}$ da Constituição Federal).

Segundo entendimento de José Afonso da Silva, as atribuições do Congresso não se resumem apenas à criação de leis. Mais do que isso, classifica-as em cinco grupos, a saber: atribuições legislativas, que correspondem à elaboração da lei formal; atribuições de fiscalização e controle; atribuições de julgamento de crimes de responsabilidade,

\footnotetext{
${ }^{4}$ Art. 49. É da competência exclusiva do Congresso Nacional:

I - resolver definitivamente sobre tratados, acordos ou atos internacionais que acarretem encargos ou compromissos gravosos ao patrimônio nacional;

II - autorizar o Presidente da República a declarar guerra, a celebrar a paz, a permitir que forças estrangeiras transitem pelo território nacional ou nele permaneçam temporariamente, ressalvados os casos previstos em lei complementar;

III - autorizar o Presidente e o Vice-Presidente da República a se ausentarem do País, quando a ausência exceder a quinze dias;

IV - aprovar o estado de defesa e a intervenção federal, autorizar o estado de sítio, ou suspender qualquer uma dessas medidas;

V - sustar os atos normativos do Poder Executivo que exorbitem do poder regulamentar ou dos limites de delegação legislativa;

VI - mudar temporariamente sua sede;

VII - fixar idêntico subsídio para os Deputados Federais e os Senadores, observado o que dispõem os arts. 37 , XI, 39, § $4^{\circ}, 150$, II, 153, III, e 153, § $2^{\circ}$, I;

VIII - fixar os subsídios do Presidente e do Vice-Presidente da República e dos Ministros de Estado, observado o que dispõem os arts. $37, \mathrm{XI}, 39, \S 4^{\circ}, 150$, II, 153 , III, e $153, \S 2^{\circ}$, I;

IX - julgar anualmente as contas prestadas pelo Presidente da República e apreciar os relatórios sobre a execução dos planos de governo;

$\mathrm{X}$ - fiscalizar e controlar, diretamente, ou por qualquer de suas Casas, os atos do Poder Executivo, incluídos os da administração indireta;

XI - zelar pela preservação de sua competência legislativa em face da atribuição normativa dos outros Poderes;

XII - apreciar os atos de concessão e renovação de concessão de emissoras de rádio e televisão;

XIII - escolher dois terços dos membros do Tribunal de Contas da União;

XIV - aprovar iniciativas do Poder Executivo referentes a atividades nucleares;

XV - autorizar referendo e convocar plebiscito;

XVI - autorizar, em terras indígenas, a exploração e o aproveitamento de recursos hídricos e a pesquisa e lavra de riquezas minerais;

XVII - aprovar, previamente, a alienação ou concessão de terras públicas com área superior a dois mil e quinhentos hectares.
} 
especialmente os crimes praticados pelo Presidente da República e seus Ministros de Estado, onde a Câmara atua como "órgão de admissibilidade do processo" e o Senado como "tribunal político" de julgamento; e, por fim, atribuições deliberativas ou meramente deliberativas, que, em suma, dizem respeito às atribuições dispostas no artigo 49 e veiculadas por meio de decretos ou regulamentos.

São, assim, os decretos legislativos atos normativos primários, "destinados a regular matérias de competência exclusiva do Congresso Nacional que tenham efeitos externos a ele; independem de sanção e de veto",

Dessa forma, sob uma ótica mais restritiva, os decretos legislativos genuínos diferem da lei em sentido formal apenas na etapa de promulgação. Ambos advêm de órgão legiferante, mas enquanto a lei formal necessita da promulgação do Presidente da República que, em sancionando aquilo que inicialmente chegou ao Congresso como projeto de lei e, posteriormente saiu do órgão como decreto, manda publicar, quem faz esse procedimento final no caso de decreto legislativo propriamente dito é o Presidente do Senado, segundo o que dispõe o artigo 48, n⿳ 28 (Título III, da mesa, Capítulo II, das atribuições) do Regimento Interno do Senado (Resolução no 93 de 1970) ${ }^{6}$.

\subsection{Procedimento}

Como a Constituição não trata expressamente quanto ao procedimento específico para o decreto legislativo, tem-se que essa tarefa ficou para o Regimento Interno Comum do Congresso Nacional.

O quorum de aprovação do decreto legislativo é o de maioria simples do artigo 47 da Constituição Federal $^{7}$. Assim, extrai-se a conclusão de que o decreto legislativo aprova-se segundo o procedimento da lei ordinária, apenas diferenciando-se no momento da promulgação: nesta feita pelo Presidente da República, naquele, pelo Presidente do Senado (na qualidade de Presidente do Congresso Nacional) que, a exemplo do chefe do Executivo, manda publicar. Diz-se, portanto, que o procedimento de aprovação é especial porque tratado pelo Regimento Interno do Congresso e pelos Regimentos Internos das duas casas e porque, também, desvinculado da sanção do Presidente da República.

\footnotetext{
${ }^{5}$ SILVA, José Afonso da. Curso de Direito Constitucional Positivo. 15º ed., São Paulo: Malheiros, 1998, p. 523.

${ }^{6}$ Art. 48. Ao Presidente compete:

(...)

XXVIII - promulgar as resoluções do Senado e os decretos legislativos;

${ }^{7}$ TEMER, Michel. Elementos de Direito Constitucional. 13º ed., São Paulo: Malheiros, 1997, p. 154.
} 
É também de se ressaltar que tais decretos deverão ser discutidos e votados segundo o sistema bicameral, ou seja, "são, obrigatoriamente, instruídos, discutidos e votados, tanto na Câmara dos Deputados como no Senado Federal"8.

Assim, têm legitimidade para a iniciativa no processo de criação do decreto legislativo o Presidente da República ou membro ou comissão do Congresso Nacional.

\section{DECRETO LEGISLATIVO E TRATADO INTERNACIONAL COMUM}

No Brasil, a adoção de um tratado internacional comum, ou seja, aquele com efeito de lei ordinária e não com status constitucional, segue a procedibilidade inerente a um dualismo moderado, pois, apesar de exigir aprovação ad referendum do Congresso Nacional, não a exige por meio de lei, antes disso, prevê tal aprovação por meio de decreto legislativo. Se o fizesse por meio de lei, estaríamos diante de um dualismo extremado9

Cumpre esclarecer que, essa diferenciação acima apontada hoje é de suma importância, especialmente após a Emenda Constitucional n ${ }^{\circ} 42$, que colocou um término na prolongada discussão sobre os efeitos dos tratados internacional. Hoje, tem-se, nos termos do $\S 3$ do Artigo $5^{\circ}$ da Constituição Federal ${ }^{10}$, que os tratados internacionais de proteção dos direitos humanos possuem hierarquia de norma constitucional. Este tratamento jurídico diferenciado se justifica, na medida em que os tratados internacionais de direitos humanos apresentam um caráter especial distinguindo-se dos tratados internacionais comuns. Enquanto estes buscam o equilíbrio e a reciprocidade de relações entre Estados-partes, aqueles transcendem os meros compromissos recíprocos entre os Estados pactuantes, tendo em vista que objetivam a salvaguarda dos direitos do ser humano e não das prerrogativas dos Estados $^{11}$.

Segundo a Constituição Federal de1988, em seu artigo 84, VIII, "compete privativamente ao Presidente da República celebrar tratados, convenções e atos

\footnotetext{
${ }^{8}$ BULOS, Uadi Lammêgo. Constituição Federal Anotada. São Paulo: Saraiva, 2000, p.739.

${ }^{9}$ Id. ibid.

${ }^{10} \S 3^{\circ}$ Os tratados e convenções internacionais sobre direitos humanos que forem aprovados, em cada Casa do Congresso Nacional, em dois turnos, por três quintos dos votos dos respectivos membros, serão equivalentes às emendas constitucionais.

${ }^{11}$ PIOVESAN, Flávia. A Incorporação, a hierarquia e o impacto dos tratados internacionais de proteção dos direitos humanos no Direito Brasileiro. In: O Sistema Interamericano de Proteção dos Direitos Humanos e o Direito Brasileiro/ coordenação Luiz Flávio Gomes, Flávia Piovesan. São Paulo: Editora Revista dos Tribunais, 2000, p. 162 e 163.
} 
internacionais, sujeitos a referendo do Congresso Nacional", que deverá fazê-lo, segundo o artigo 49, com competência exclusiva, por meio de decreto legislativo.

Como já informado, o decreto legislativo, uma das espécies normativas previstas no artigo 59, em seu inciso VI, não tem previsão constitucional para o seu procedimento, ficando a tarefa para o Regimento Interno Comum do Congresso, bem como, no tocante às tramitações em cada casa, para o Regimento da Câmara dos Deputados e o Regimento do Senado.

\subsection{Procedimento}

A legitimidade, tanto para iniciar uma negociação bilateral ou multilateral, como para apresentar ao Congresso um tratado internacional comum para a efetiva aprovação legislativa e posterior confirmação de adesão, é do Presidente da República, nos termos do artigo 84, VIII, da Constituição Federal.

É, entretanto, competência privativa, na sua condição de chefe de Estado. Isso significa dizer que, tem o Presidente da República a possibilidade de delegar essa tarefa de negociação, por meio de um instrumento chamado de "plenos poderes"12, para o Ministério das Relações Exteriores, que é o órgão competente no estabelecimento de relações diplomáticas em nome do Estado brasileiro.

Assim, quando essa função for desempenhada pelo representante do Ministério das Relações Exteriores, por meio da Divisão de Atos Internacionais, o acordo celebrado deverá ser ratificado pelo Presidente da República antes de ser submetido ao Congresso. Esse já era o entendimento na vigência da Constituição de 1967, com a posterior emenda constitucional $\mathrm{n}^{\circ}$ 1 de 1969. Nesse sentido se manifestava Pontes de Miranda: "quando algum tratado, convenção, ou acordo, é firmado por embaixador, ou outros diplomatas, ou pessoa com poderes, o Presidente da República tem de ratificá-lo"13.

Importante salientar a respeito dessa delegação de poderes, pois, segundo Antônio Paulo Cachapuz de Medeiros, atualmente essa é a forma mais comum utilizada no Brasil de negociações de tratados internacionais comuns. Para ele, "o Itamaraty exerce, assim, controle absoluto sobre a participação do Brasil no processo de formação de acordos internacionais,

\footnotetext{
12 MEDEIROS, Antônio Paulo Cachapuz de. O poder de celebrar Tratados. Competência dos poderes constituídos para a celebração de tratados, à luz do Direito Internacional, do Direito Comparado e do Direito Constitucional Brasileiro. Porto Alegre: Sergio Antonio Fabris Editor, 1995, p. 459.

${ }^{13}$ MIRANDA, op. cit., p. 105.
} 
sendo esses discutidos, acompanhados e assinados, durante sua elaboração, por agentes diplomáticos brasileiros" $" 14$.

A proposta de tratado internacional chega ao Congresso por meio de um documento denominado mensagem, que se compõe do texto do tratado propriamente dito mais uma exposição de motivos. Se o acordo tiver sido assinado pelo Ministro das Relações Exteriores, a mensagem com o texto, mais a exposição dos motivos da assinatura passam, primeiro pelo Presidente da República que, em aceitando-o, encaminha-o para o Congresso Nacional para a devida apreciação.

Por seguir a ritualística bicameral e, por tratar-se de iniciativa do Presidente da República, uma vez no Congresso Nacional tal tratado será primeiramente apreciado na Câmara dos Deputados pela Comissão Permanente de Relações Exteriores e Defesa Nacional (artigo 32, XI, c, do Regimento Interno da Câmara ${ }^{15}$ ). Observe-se que ao chegar na Câmara, o Presidente da casa deverá distribuir o projeto primeiro para a Comissão pertinente à matéria e, posteriormente para a Comissão de Constituição e Justiça e outras mais que sejam necessárias, antes da conseqüente decisão (artigo 53, Regimento Interno da Câmara ${ }^{16}$ ).

Após a apreciação nesta Comissão, que deverá voltar atenção para o mérito (artigo 53, I, Regimento Interno da Câmara), o projeto segue para a Comissão de Constituição e Justiça e Redação (artigo 32, III, do Regimento Interno da Câmara ${ }^{17}$ ) onde terá analisada a sua

\footnotetext{
${ }^{14}$ MEDEIROS, loc. cit.

${ }^{15}$ Art. 32. São as seguintes as Comissões Permanentes e respectivos campos temáticos ou áreas de atividade:

(...)

XI - Comissão de Relações Exteriores e de Defesa Nacional:

(...)

c) tratados, atos, acordos e convênios internacionais e demais instrumentos de política externa;

16 Art. 53. Antes da deliberação do Plenário, ou quando esta for dispensada, as proposições, exceto os requerimentos, serão apreciadas:

I - pelas Comissões de mérito a que a matéria estiver afeta;

II - pela Comissão de Finanças e Tributação, para o exame dos aspectos financeiro e orçamentário públicos, quanto à sua compatibilidade ou adequação com o plano plurianual, a lei de diretrizes orçamentárias e o orçamento anual, e para o exame do mérito, quando for o caso;

III - pela Comissão de Constituição e Justiça e de Redação, para o exame dos aspectos de constitucionalidade, legalidade, juridicidade, regimentalidade e de técnica legislativa, e, juntamente com as Comissões técnicas, para pronunciar-se sobre o seu mérito, quando for o caso;

IV - pela Comissão Especial a que se refere o art. 34, inciso II, para pronunciar-se quanto à admissibilidade jurídica e legislativa e, quando for o caso, a compatibilidade orçamentária da proposição, e sobre o mérito, aplicando-se em relação à mesma o disposto no artigo seguinte.

${ }^{17}$ Art. 32. São as seguintes as Comissões Permanentes e respectivos campos temáticos ou áreas de atividade III - Comissão de Constituição e Justiça e de Redação:

a) aspectos constitucional, legal, jurídico, regimental e de técnica legislativa de projetos, emendas ou substitutivos sujeitos à apreciação da Câmara ou de suas Comissões;

b) admissibilidade de proposta de emenda à Constituição;

c) assunto de natureza jurídica ou constitucional que lhe seja submetido, em consulta, pelo Presidente da Câmara, pelo Plenário ou por outra Comissão, ou em razão de recurso previsto neste regimento;

d) assuntos atinentes aos direitos e garantias fundamentais, à organização do Estado, à organização dos Poderes e às funções essenciais da Justiça;
} 
constitucionalidade, legalidade, juridicidade, regimentalidade e técnica legislativa (artigo 53, III, Regimento Interno da Câmara).

Importante notar que ao sair da primeira Comissão e ser encaminhado para a Comissão de Constituição e Justiça e Redação, o parecer do relator já é um projeto de Decreto Legislativo com caráter de urgência, nos termos do artigo 151, I, j do Regimento Interno da Câmara $^{18}$, que terá como conseqüência, a apreciação da matéria em discussão única em plenário $^{19}$.

A aprovação em plenário, como já mencionado, se dá pela maioria simples do artigo 47 da Constituição Federal. Assim, vencida esta etapa, remete-se o projeto para o Senado.

Uma vez no Senado, o projeto de Decreto Legislativo para aprovação de Tratado Internacional segue rito parecido com o da Câmara. Primeiro, é distribuído pelo Presidente da casa para a primeira Comissão permanente que é a Comissão de Relações Exteriores e Defesa Nacional, prevista no artigo 103 do Regimento Interno do Senado ${ }^{20}$.

e) matérias relativas a direito constitucional, eleitoral, civil, penal, penitenciário, processual, notarial;

f) partidos políticos, mandato e representação política, sistemas eleitorais e eleições;

g) registros públicos;

h) desapropriações;

i) nacionalidade, cidadania, naturalização, regime jurídico dos estrangeiros; emigração e imigração;

j) intervenção federal;

l) uso dos símbolos nacionais;

$m$ )criação de novos Estados e Territórios; incorporação, subdivisão ou desmembramento de áreas de Estados ou de Territórios;

n) transferência temporária da sede do Governo;

o) anistia;

p) direitos e deveres do mandato; perda de mandato de Deputado, nas hipóteses dos incisos I, II e VI do art. 55

da Constituição Federal; pedidos de licença para incorporação de Deputados às Forças Armadas;

q) redação do vencido em Plenário e redação final das proposições em geral;

${ }^{18}$ Art. 151. Quanto à natureza de sua tramitação podem ser:

I - urgentes as proposições:

(...)

j) oriundas de mensagens do Poder Executivo que versem sobre acordos, tratados, convenções, pactos, convênios, protocolos e demais instrumentos de política internacional, a partir de sua aprovação pelo órgão técnico específico, através de projeto de decreto legislativo, ou que sejam por outra forma apreciadas conclusivamente;

${ }^{19}$ MEDEIROS, op. cit. p. 464.

${ }^{20}$ Art. 103. À Comissão de Relações Exteriores e Defesa Nacional compete emitir parecer sobre:

I - proposições referentes aos atos e relações internacionais (Const., art. 49, I) e ao Ministério das Relações Exteriores;

II - comércio exterior;

III - indicação de nome para chefe de missão diplomática de caráter permanente junto a governos estrangeiros e das organizações internacionais de que o Brasil faça parte (Const., art. 52, IV);

IV - requerimentos de votos de censura, de aplauso ou semelhante, quando se refiram a acontecimentos ou atos públicos internacionais;

V - Forças Armadas de terra, mar e ar, requisições militares, passagem de forças estrangeiras e sua permanência no território nacional, questões de fronteiras e limites do território nacional, espaço aéreo e marítimo,

declaração de guerra e celebração de paz (Const., art. 49, II);33 VI - assuntos referentes à Organização das Nações Unidas e entidades internacionais de qualquer natureza;

VII - autorização para o Presidente ou o Vice-Presidente da República se ausentarem do território nacional (Const., art. 49, III); 
A tramitação do projeto, dentro do Senado, a exemplo da Câmara segue um rito de urgência e vem expressa no artigo 376 do respectivo Regimento Interno ${ }^{21}$.

$\mathrm{O}$ artigo 171 do mesmo Regimento ${ }^{22}$ dispõe que as matérias que dependam de exame nas respectivas comissões só serão incluídas na Ordem do Dia após serem emitidos os pareceres devidamente lidos na Hora do Expediente e publicados no Diário do Senado Federal. Com a questão dos tratados internacionais, entretanto, essa regra sofre uma exceção. É o que dispõe o artigo 172 , II, $\mathrm{c}^{23}$, quando expressa a possibilidade do Decreto Legislativo referente à tratado internacional comum ser incluído na Ordem do Dia sem o devido parecer das comissões.

A Comissão de Relações Exteriores e Defesa Nacional tem competência para apreciar a matéria de maneira terminativa, ou seja, encerrada essa fase (processo nominal e votação com maioria simples segundo critério do artigo 47 da Constituição Federal) a decisão da Comissão é levada ao Presidente do Senado, que dá ciência ao Plenário e manda publicar no Diário do Congresso $\mathrm{Nacional}^{24}$.

Após publicação, o prazo para recurso é de cinco dias. Ao término do prazo, conforme o artigo $91^{25}$, o projeto é promulgado ou remetido de volta para a Câmara, caso haja alteração.

VIII - outros assuntos correlatos.

Parágrafo único. A Comissão integrará, por um de seus membros, as comissões enviadas pelo Senado ao exterior, em assuntos pertinentes à política externa do País.

${ }^{21}$ Art. 376. O projeto de decreto legislativo referente a atos internacionais terá a seguinte tramitação:

I - só terá iniciado o seu curso se estiver acompanhado de cópia autenticada do texto, em português, do ato internacional respectivo, bem como da mensagem de encaminhamento e da exposição de motivos;

II - lido no Período do Expediente, será o projeto publicado e distribuído em avulsos, acompanhado dos textos referidos no inciso I e despachado à Comissão de Relações Exteriores e Defesa Nacional;8 III - perante a Comissão, nos cinco dias úteis subseqüentes à distribuição de avulsos, poderão ser oferecidas emendas; a Comissão terá, para opinar sobre o projeto, e emendas, o prazo de quinze dias úteis, prorrogável por igual período;

IV - publicados o parecer e as emendas e distribuídos os avulsos, decorrido o interstício regimental, a matéria será incluída em Ordem do Dia;

V - não sendo emitido o parecer, conforme estabelece o inciso III, aplicar-se-á o disposto no art. 172, II, $c$.

${ }^{22}$ Art. 171. A matéria dependente de exame das comissões só será incluída em Ordem do Dia depois de emitidos os pareceres, lidos no Período do Expediente, publicados no Diário do Senado Federal e distribuídos em avulsos, observado o interstício regimental (arts. 280 e 281).

${ }_{23}$ Art. 172. A inclusão em Ordem do Dia de proposição em rito normal, sem que esteja instruída com pareceres das comissões a que houver sido distribuída, só é admissível nas seguintes hipóteses:

(...)

II - por ato do Presidente, quando se tratar:

(...)

c) de projeto de decreto legislativo referente a tratado, convênio ou acordo internacional, se faltarem dez dias, ou menos, para o término do prazo no qual o Brasil deva manifestar-se sobre o ato em apreço;

${ }^{24}$ MEDEIROS, op. cit. p. 465.

${ }^{25}$ Art. 91. Às comissões, no âmbito de suas atribuições, cabe, dispensada a competência do Plenário, nos termos do art. 58, § $2^{\circ}$, I, da Constituição, discutir e votar:

I - projetos de lei ordinária de autoria de Senador, ressalvado projeto de código;

II - projetos de resolução que versem sobre a suspensão da execução, no todo ou em parte, de lei declarada inconstitucional por decisão definitiva do Supremo Tribunal Federal (Const., art. 52, X). 
Se aprovado, o projeto transforma-se em Decreto Legislativo e é sempre promulgado pelo Presidente do Senado (ainda que tiver voltado para a Câmara), que o manda para a devida publicação no Diário Oficial da União e no Diário Oficial do Congresso Nacional ${ }^{26}$.

Após o término do procedimento legislativo, o tratado internacional estará pronto para a ratificação do Presidente da República, que é o ato discricionário de que dispõe tal autoridade para aceitação definitiva do tratado. Em havendo essa ratificação, o Presidente estará vinculado ao compromisso e, portanto, por meio de um Decreto Executivo, promulgao, momento em que o tratado é incorporado na ordem interna. Por fim, o texto integral é publicado no Diário Oficial da União.

O momento da ratificação presidencial é o momento em que o tratado entra em vigor internacionalmente. Essa ratificação é o ato em que os Estados signatários promovem a comunicação a respeito da aceitação do acordo e, segundo Antônio Paulo Cachapuz de Medeiros, se dá de duas formas: por meio de troca, se for um acordo bilateral, e por meio de depósito, se relativo a acordo multilateral. ${ }^{27}$.

Cumpre um pequeno esclarecimento no tocante à terminologia empregada. Os autores divergem quanto ao termo ratificação. Para alguns, esse seria o momento em que o tratado internacional é aprovado legislativamente, sendo, portanto, termo inerente ao ato do Congresso Nacional. Para outros, entretanto, este é o termo mais correto para designar o momento em que o Presidente da República informa os demais Estados signatários a sua vontade de cumprir os termos do acordo.

$\S$ 1o O Presidente do Senado, ouvidas as lideranças, poderá conferir às comissões competência para apreciar, terminativamente, as seguintes matérias:

I - tratados ou acordos internacionais (Const., art. 49, I);

II - autorização para a exploração e o aproveitamento de recursos hídricos e a pesquisa e lavra de riquezas minerais em terras indígenas (Const., art. 49, XVI);

III - alienação ou concessão de terras públicas com área superior a dois mil e quinhentos hectares (Const., art. 49, XVII);

IV - projetos de lei da Câmara de iniciativa parlamentar que tiverem sido aprovados, em decisão terminativa, por comissão daquela Casa;

$\mathrm{V}$ - indicações e proposições diversas, exceto:

a) projeto de resolução que altere o Regimento Interno;

b) projetos de resolução a que se referem os arts. 52, V a IX, e 155, §§ 1o, IV, e 2o , IV e V, da Constituição;

c) proposta de emenda à Constituição.

§ 2o Encerrada a apreciação terminativa a que se refere este artigo, a decisão da comissão será comunicada ao Presidente do Senado Federal para ciência do Plenário e publicação no Diário do Senado Federal.

§ 3o No prazo de cinco dias úteis, contado a partir da publicação da comunicação referida no § 2o no avulso da Ordem do Dia da sessão seguin te, poderá ser interposto recurso para apreciação da matéria pelo Plenário do Senado.

§ 4o O recurso, assinado por um décimo dos membros do Senado, será dirigido ao Presidente da Casa.

$\S 50$ Esgotado o prazo previsto no $\S 30$, sem interposição de recurso, o projeto será, conforme o caso, encaminhado à sanção, promulgado, remetido à Câmara ou arquivado.

${ }^{26}$ MEDEIROS, op. cit. p. 466.

${ }^{27}$ Id. ibid., p. 469. 
Para Francisco Rezek, o termo ratificação designa um ato internacional de governo e, portanto, diz respeito ao momento em que o Presidente da República informa de sua aquiescência, após devidamente aprovado pelo órgão legiferante, ao acordo firmado ${ }^{28}$. Restanos, aqui, acatar tal entendimento, adotando a terminologia aprovação como a mais apropriada para o momento em que o Congresso Nacional se manifesta pela aceitação do Tratado Internacional.

Outro problema que se coloca no tocante aos Tratados Internacionais é quanto a interpretação do artigo 49, I da Constituição Federal. Isso porque há quem afirme que nem todo acordo internacional deva passar pelo crivo do Congresso Nacional, apenas aqueles "encargos ou compromissos gravosos ao patrimônio nacional".

Não é esse, no entanto, o entendimento de Manoel Gonçalves Ferreira Filho, para quem, "a redação inadequada deste inciso não importa em excluir, como parece, a necessidade de aprovação por parte do Congresso Nacional de atos internacionais, celebrados pelo Presidente da República, como tratados e convenções, que não pesem diretamente sobre o patrimônio nacional" ${ }^{29}$. Apesar do equívoco, diz ele, quis o legislador atestar a segurança jurídica, o que o fez prevendo, no artigo 84, VIII ${ }^{30}$ a necessidade do referendo do Congresso.

Entretanto, na prática o que ocorre, é a existência de certos atos chamados de Acordos Executivos que contemplam, para a sua aprovação, um procedimento simples e abreviado. Prescindem, esses acordos, da aprovação individualizada do Congresso Nacional.

Para Francisco Rezek, esses acordos são válidos, desde que tenham apenas por objetivo consignar a interpretação de algumas cláusulas de tratado já aprovado; desde que constituam complemento de tratado já existente; e que objetivem abrir caminho para novas negociações futuras, e desde que não alterem o conteúdo do tratado existente ${ }^{31}$.

Esses acordos, no entendimento de Antônio Paulo Cachapuz de Medeiros, observam um procedimento bastante simplificado. Não sendo promulgados por meio de decretos, têm apenas três fases: negociação, assinatura e promulgação (com posterior publicação no Diário Oficial da União autorizada pelo Ministro das Relações Exteriores) ${ }^{32}$.

\footnotetext{
${ }^{28}$ REZEK, J. Francisco. Direito Internacional Público. Curso Elementar. $8^{\circ}$ ed., São Paulo: Saraiva, 2000, p. 49.

${ }^{29}$ FERREIRA Filho. Comentários à Constituição Brasileira de 1988. $2^{\circ}$ ed., São Paulo: Saraiva, vol. I, 1997, p. 296.

${ }^{30}$ Art. 84. Compete privativamente ao Presidente da República:

(...)

VIII - celebrar tratados, convenções e atos internacionais, sujeitos a referendo do Congresso Nacional;

${ }^{31}$ REZEK, op. cit., p. 62.

${ }^{32}$ MEDEIROS, op. cit., p. 473.
} 


\section{CONTOLE DE CONSTITUCIONALIDADE}

Decreto Legislativo, via de regra, e de acordo como o que dispõe o artigo 59 da Constituição Federal, são atos normativos primários.

Entretanto, alguns autores não compartilham desse entendimento. É o caso de Manoel Gonçalves Ferreira Filho para quem os Decretos Legislativos são, ao lado das resoluções, "atos a que falta o caráter de instauração de normas gerais e abstratas",33. Para ele, os incisos do artigo 49 da Constituição não possuem caráter normativo como as leis.

Luiz Alberto David Araújo, por sua vez, vai mais longe. Para o autor, os incisos que não possuem caráter normativo, ou seja, que veiculam matéria concreta, são o III, IV, V, VI, IX, XII, XIII, XIV, XV, XVI, e XVII ${ }^{34}$. Confirma, ainda, que os incisos VII e VIII possuem a normatividade esperada. Entretanto, nada fala sobre o inciso I, referente aos tratados internacionais.

Seguindo essa linha, há autores que definem o Decreto Legislativo como um ato próprio da Administração Pública, podendo, assim, serem tidos como "um ato administrativo da competência congressual, ou seja, integraria mais o poder de ditar normas de caráter administrativo que aquele caráter legislativo" ${ }^{\text {"3 }}$.

Entretanto, data vênia, tal entendimento não pode prosperar. Isso porque, pela melhor doutrina de direito administrativo, o ato administrativo pode ser considerado como sendo todo aquele praticado na função administrativa.

Partindo desse ponto, teríamos algumas modalidades de atos administrativos, que quanto à forma poderiam ser divididos em decretos, resoluções e portarias, circulares, despachos e alvarás. Seriam os decretos os atos inerentes à figura do Chefe do Executivo (da União, dos estados-membros e dos municípios), dotados tanto de individualidade (revestido como norma individual de efeito concreto) quanto de generalidade (quando, a exemplo da lei, se constituem em regras gerais e abstratas) ${ }^{36}$.

Seguindo essa linha teórica de desarmar a normatividade dos incisos do artigo 49 da Constituição, a conseqüência imediata é, sem dúvida alguma, a impossibilidade de controle de constitucionalidade desses Decretos Legislativos.

\footnotetext{
${ }^{33}$ Do Processo Legislativo. $5^{\circ}$ ed., São Paulo: Saraiva, 2002, p. 197.

${ }^{34}$ ARAUJO, Luiz Alberto David e NUNES Júnior, Vidal Serrano. Curso de Direito Constitucional. $5^{\circ}$ ed., São Paulo: Saraiva, 2001, p. 308.

${ }^{35}$ BASTOS, Celso Ribeiro e MARTINS, Ives Gandra. Comentários à Constituição do Brasil. $2^{\circ}$ ed., vol. $4^{\circ}$, Tomo I, São Paulo: Saraiva, 2000, p. 314.

${ }^{36}$ DI PIETRO, Maria Sylvia Zanella. Direito Administrativo. $9^{\circ}$ ed., São Paulo: Atlas, 1997, p.192.
} 
Entretanto, tal impossibilidade não pode prosperar.

O controle de constitucionalidade, que pode ser preventivo (realizado ainda sobre o projeto em tramitação legislativa por meio da Comissão de Constituição e Justiça), ou repressivo (que assume duas modalidades, a concreta e a abstrata), incide sobre lei ou ato normativo, ou seja, sobre atos que sejam compostos de generalidade e abstração. Fica, portanto, a lei de efeito concreto, muito embora ato legislativo, fora do âmbito de controle de constitucionalidade por não possuir os elementos essenciais acima citados.

Assim, acatar o Decreto Legislativo como mero ato administrativo congressual é suportar a idéia de impossibilidade de seu controle de constitucionalidade. O que geraria sérias inconstitucionalidades ao longo do ordenamento, já que o artigo 49 é o que específica a atuação exclusiva do Congresso, que deverá, em regra, também estar de acordo com a Constituição Federal.

É o que defende Clèmerson Merlin Clève, para quem tanto os Decretos Legislativos quanto as Resoluções são atos legislativos que dispõem de força de lei. Assim "desde que veiculem atos normativos, estão sujeitos à fiscalização abstrata da constitucionalidade"37.

Em relação aos tratados internacionais, o mesmo autor se manifesta no sentido da impossibilidade do controle de constitucionalidade. Esse só seria possível quanto ao Decreto Legislativo que o aprova, nunca contra o tratado propriamente dito. Isso porque, seriam os tratados internacionais atos bilaterais ou multilaterais de direito internacional, não podendo uma decisão interna anulá-los. "Assim, a declaração de inconstitucionalidade parece atingir, tão somente, as normas nacionais de aprovação, ratificação e promulgação. No que concerne ao complexo normativo estabelecido no tratado ou convenção, há que se admitir que o juízo de inconstitucionalidade resolve-se na desaplicação, não se afigurando possível a decretação da nulidade, na espécie" ${ }^{38}$.

No mesmo sentido, Gilmar Ferreira Mendes, comparando os ordenamentos brasileiro e alemão, defende a possibilidade de controle de constitucionalidade por via direta de ação, contra o Decreto do Chefe do Executivo, que ratifica o tratado internacional, haja vista, possuir esse ato a aplicação geral e obrigatória ${ }^{39}$.

Por fim, cumpre ressaltar que, discussões a parte em relação à possibilidade de controle de constitucionalidade sobre o tratado internacional, este, como já demonstrado aqui, passa necessariamente pelo crivo das duas casas do Congresso antes de ser ratificado pelo

\footnotetext{
${ }^{37}$ CLÈVE, Clèmerson Merlin. A Fiscalização Abstrata da Constitucionalidade no Direito Brasileiro. $2^{\circ}$ ed., São Paulo: Revista dos Tribunais, 2000, p. 207.

${ }^{38}$ Id. ibid., p. 209.

${ }^{39}$ MENDES, Gilmar Ferreira. Jurisdição Constitucional. $2^{\circ}$ ed., São Paulo: Saraiva, 1988, p. 168.
} 
Presidente da República, e, em pelo menos uma, recebe a análise de uma Comissão de Constituição e Justiça, que entre outras coisas, analisa exatamente a constitucionalidade do projeto em tramitação, antes de dar o aval final para que o Decreto Legislativo seja aprovado e dê poderes para que o Presidente da República, em um ato final, ratifique, promulgue e mande publicar o novo Tratado Internacional, que só a partir disso, fará parte do ordenamento pátrio. Contempla, portanto, um processo de controle preventivo de constitucionalidade, quando, antes de ser um tratado internacional, é ainda um Decreto Legislativo.

\section{CONSIDERAÇÕES FINAIS}

Decretos legislativos são atos normativos primários. Ou seja, possuem caráter de normas gerais e abstratas.

Assim, espécie normativa prevista no artigo 59 da Constituição Federal, o decreto legislativo é o instrumento que viabiliza a atuação do Congresso Nacional, ou seja, é o instrumento que veicula as matérias de competência exclusiva do Congresso previstas no artigo 49 da magna carta.

Como regulam matérias de competência exclusiva do Congresso Nacional, os decretos legislativos têm por característica peculiar, independer de sanção ou veto presidencial, diferenciando-se, portanto, das leis, na etapa de promulgação.

A Constituição Federal calou-se quanto ao procedimento do decreto legislativo. Por isso, coube ao Regimento Interno Comum do Congresso Nacional essa tarefa, estabelecendo um sistema bicameral de discussão e votação, tanto na Câmara dos Deputados quanto no Senado.

Em que pese a Emenda Constitucional $n^{\circ} 42$ definir que os tratados internacionais de proteção dos direitos humanos possuem hierarquia de norma constitucional e, portanto, necessitam de uma aprovação diferenciada equiparada a uma emenda constitucional ${ }^{40}$, os tratados internacionais comuns ainda dependem de decreto legislativo para a sua viabilização.

Os tratados internacionais comuns, para a sua aprovação, seguem a procedibilidade inerente a um dualismo moderado, com aprovação ad referendum do Congresso Nacional através de um decreto legislativo, naquilo que dispõe o artigo 49, inciso I da Constituição Federal.

\footnotetext{
${ }^{40}$ Art. $5^{\circ}(\ldots)$

$\S 3^{\circ}$ Os tratados e convenções internacionais sobre direitos humanos que forem aprovados, em cada Casa do Congresso Nacional, em dois turnos, por três quintos dos votos dos respectivos membros, serão equivalentes às emendas constitucionais.
} 
Por fim, é de se esclarecer que os decretos legislativos, como são atos normativos primários, ou seja, dispõem de força de lei, submetem-se à fiscalização abstrata da insconstitucionalidade. Assim, forçoso concluir que o tratado internacional não pode ser nunca objeto de controle de constitucionalidade, mas o decreto legislativo que o aprova, sim.

\section{BIBLIOGRAFIA}

ACCIOLY, Hildebrando. Manual de Direito Internacional Público. $13^{\circ}$ ed., São Paulo: Saraiva, 1998.

ARAUJO, Luiz Alberto David e NUNES Júnior, Vidal Serrano. Curso de Direito Constitucional. $5^{\circ}$ ed., São Paulo: Saraiva, 2001.

BAHIA, Saulo José Casali. Tratados Internacionais no Direito Brasileiro. Rio de Janeiro: Forense, 2000.

BARROSO, Luís Roberto. Constituição da República Federativa do Brasil Anotada. $3^{\circ}$ ed., São Paulo: Saraiva, 2001.

BASTOS, Celso Ribeiro. Curso de Direito Constitucional. $22^{\circ}$ ed., São Paulo: Saraiva, 2001. e MARTINS, Ives Gandra. Comentários à Constituição do Brasil. $2^{\circ}$ ed., vol. $1^{\circ}$, São Paulo: Saraiva, 2000.

e MARTINS, Ives Gandra. Comentários à Constituição do Brasil. $2^{\circ}$ ed., vol. 4ºmo I e II, São Paulo: Saraiva, 2000.

BULOS, Uadi Lammêgo. Constituição Federal Anotada. São Paulo: Saraiva, 2000.

CLÈVE, Clèmerson Merlin. A Fiscalização Abstrata da Constitucionalidade no Direito Brasileiro. $2^{\circ}$ ed., São Paulo: Revista dos Tribunais, 2000. 
COSTA, Elcias Ferreira da. Comentários Breves à Constituição Federal. Porto Alegre: Sergio Antônio Fabris Editor, 1989.

DI PIETRO, Maria Sylvia Zanella. Direito Administrativo. 9º ed., São Paulo: Atlas, 1997.

FERREIRA Filho, Manoel Gonçalves. Comentários à Constituição Brasileira. $3^{\circ}$ ed., São Paulo: Saraiva, 1983.

. Comentários à Constituição Brasileira de 1988. $2^{\circ}$ ed., São Paulo: Saraiva, vol. I, 1997.

. Curso de Direito Constitucional. 26º ed., São Paulo: Saraiva, 1999.

. Do Processo Legislativo. $5^{\circ}$ ed., São Paulo: Saraiva, 2002.

LIMA, Sérgio Mourão Corrêa. Tratados Internacionais no Brasil e Interação. São Paulo: LTR, 1998.

MEDEIROS, Antônio Paulo Cachapuz de. O poder de celebrar Tratados. Competência dos poderes constituídos para a celebração de tratados, à luz do Direito Internacional, do Direito Comparado e do Direito Constitucional Brasileiro. Porto Alegre: Sergio Antonio Fabris Editor, 1995.

MENDES, Gilmar Ferreira. Jurisdição Constitucional. 2º ed., São Paulo: Saraiva, 1988.

MIRANDA, Pontes de. Comentários à Constituição de 1967. Tomo III, São Paulo: Revista dos Tribunais, 1973.

MORAES, Alexandre de. Constituição do Brasil Interpretada e Legislação Constitucional. São Paulo: Atlas, 2002.

Direito Constitucional. $2^{\circ}$ ed., São Paulo: Atlas, 1997. 
PACÍFICO, Andréa Maria Calazans Pacheco. Os Tratados internacionais e o Direito Constitucional Brasileiro. Brasília: Brasília Jurídica, 2002.

PIOVESAN, Flávia. A Incorporação, a hierarquia e o impacto dos tratados internacionais de proteção dos direitos humanos no Direito Brasileiro. In: O Sistema Interamericano de Proteção dos Direitos Humanos e o Direito Brasileiro/ coordenação Luiz Flávio Gomes, Flávia Piovesan. São Paulo: Editora Revista dos Tribunais, 2000.

REZEK, J. Francisco. Direito Internacional Público. Curso Elementar. $8^{\circ}$ ed., São Paulo: Saraiva, 2000.

RODAS, João Grandino. Tratados Internacionais. São Paulo: Revista dos Tribunais, 1991.

SILVA, José Afonso da. Curso de Direito Constitucional Positivo. $15^{\circ}$ ed., São Paulo: Malheiros, 1998.

TEMER, Michel. Elementos de Direito Constitucional. 13º ed., São Paulo: Malheiros, 1997. 